\title{
Highly Selective Hg (II) Ion Detection Based on Linear Blue-Shift of the Maximum Absorption Wavelength of Silver Nanoparticles
}

\author{
Li Ping Wu, ${ }^{1}$ Hua Wen Zhao, ${ }^{1}$ Zhu Hong Qin, ${ }^{1,2}$ Xian Ying Zhao, ${ }^{1}$ and Wen Dan Pu ${ }^{1,2}$ \\ ${ }^{1}$ Department of Chemistry, Third Military Medical University, Chongqing 400038, China \\ ${ }^{2}$ College of Chemistry and Chemical Engineering, MOE Key Laboratory on Luminescence and Real-Time Analysis, Southwest \\ University, Chongqing 400715, China
}

Correspondence should be addressed to Hua Wen Zhao, sydzhw@yahoo.com.cn

Received 5 November 2011; Accepted 1 February 2012

Academic Editor: Dario Compagnone

Copyright ( $) 2012$ Li Ping Wu et al. This is an open access article distributed under the Creative Commons Attribution License, which permits unrestricted use, distribution, and reproduction in any medium, provided the original work is properly cited.

\begin{abstract}
A new method of detecting $\mathrm{Hg}$ (II) ion with silver nanoparticles (AgNPs) is developed in this contribution. When Hg (II) ions were added into AgNPs solution, the solution displayed rapid color change and blue shift of the maximum absorption wavelength $(\Delta \lambda)$, which was in proportion to the $\mathrm{Hg}$ (II) ion concentration over the range of $2.0 \times 10^{-7}-6.0 \times 10^{-6} \mathrm{~mol} / \mathrm{L}$, with detection limit $(3 \sigma)$ of $6.6 \times 10^{-9} \mathrm{~mol} / \mathrm{L}$. Under the same experimental conditions, other metal ions did not interfere. Thus, we propose a rapid, simple and highly selective method for detecting $\mathrm{Hg}$ (II) ion.
\end{abstract}

\section{Introduction}

Hg (II), a widespread heavy metal, has been widely recognized as one of the most hazardous pollutants and highly carcinogenic materials due to its accumulative and toxic properties in the environment [1]. Accumulative properties of mercury may cause serious harm to human beings and animals. Moreover, $\mathrm{Hg}$ (II) can be transformed into methylmercury by bacteria [2], from which several serious disorders may arise, including sensory, mental, and neural damage [3]. Therefore, environmental monitoring of aqueous mercury becomes an increasing demand. By this time, methods of detecting mercury have been reported, such as colorimetric methods [4-7], atomic absorption spectrometry $[8,9]$, inductively coupled plasma mass spectrometry [10], mercury sensors with gold nanorods [11], and gold nanoparticles [12]. Although these methods have good sensitivity and selectivity, they are cost and time consuming. Therefore, it is necessary to develop a simple and rapid method.

Metal nanoparticles have been extensively studied and used because of their attractive optical, electronic, biological, and catalytic properties [13]. AgNPs have been paid more attention for special properties such as higher extinction coefficients, catalytically active and exhibiting Raman enhancement properties $[14,15]$. Because of these properties, AgNPs are widely used in molecular imaging of cancer cells as probes for microscopy [16], antibacterial applications $[17,18]$, and so on. In this paper, we propose a simple and rapid method for $\mathrm{Hg}$ (II) ion using AgNPs.

\section{Experimental}

2.1. Reagents. Silver nitrate, trisodium citrate dihydrate, sodium borohydride, calcium chloride hexahydrate, cadmium chloride, and sodium chloride were purchased from Kelong Chemical Reagent Plant in Chengdu. Mercury (II) chloride, lead (II) nitrate, sodium nitrate, and magnesium chloride hexahydrate were purchased from Bo Yi, Chongqing Chemical Reagent Co., Ltd. Cupric sulfate and aluminum sulfate were obtained from Tianjin Damao Chemical Reagent Factory. Zinc chloride was obtained from Chongqing Inorganic Chemical Reagent Factory. All chemicals used in the experiment are analytical reagent grade without further purification. All water used is deionized water.

2.2. Apparatus. The absorption spectrum of AgNPs was measured on a TU-1901 UV-vis spectrophotometer (Beijing Purkinje General Instrument Company). The shape of 


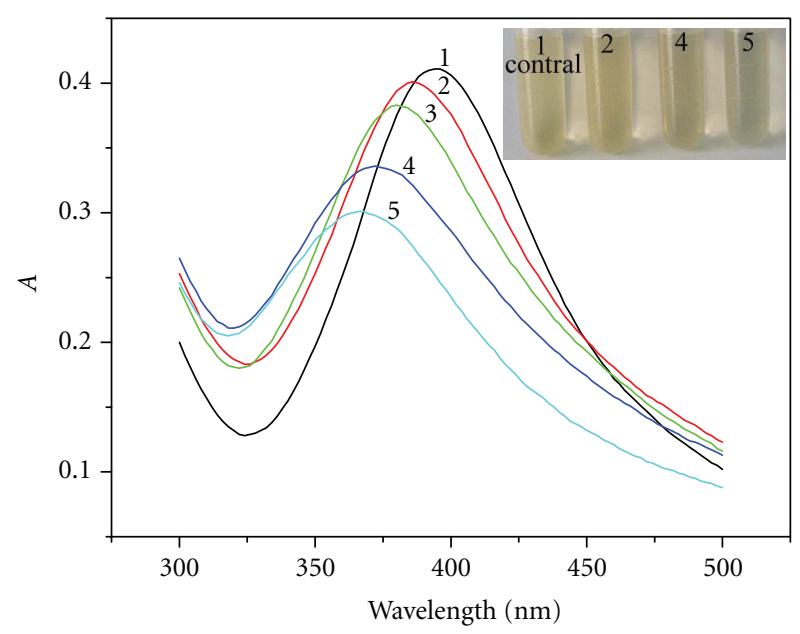

FIgURE 1: The absorption spectrum of AgNPs in the absence and presence of $\mathrm{Hg}$ (II) ion. (The inset picture displays color change corresponding to the curves: the solution color gradually changed from yellow to colorless.) Concentration: AgNPs: $6.5 \times 10^{-5} \mathrm{~mol} / \mathrm{L}$; $\mathrm{Hg}$ (II) ion (from 1 curve to $5, \times 10^{-6} \mathrm{~mol} / \mathrm{L}$ ): $0,1.2,3.2,4.8,6.0$; HAc-NaAc buffer (pH 5.6).

AgNPs was imaged with a Hitachi S-4800 scanning electron microscopy (Tokyo, Japan). XW-80A vortex mixer purchased from Shanghai Jingke Industrial Co., Ltd was used to mix solutions. Reagents were exactly quantified by electronic balance, which was purchased from Sartorius Scientific Instrument (Beijing) Co., Ltd.

2.3. Preparation of AgNPs. AgNPs were prepared according to a previously published method [19]. $2 \mathrm{~mL}$ of $5 \%$ trisodium citrate solution was added to $100 \mathrm{~mL}$ solution of $0.5 \mathrm{mM} \mathrm{AgNO}_{3}$ under vigorously stirring. Then, $2 \mathrm{~mL}$ of sodium borohydride diluted solution was added into the above solution. AgNPs were formed rapidly and continuously stirred for $30 \mathrm{~min}$. The AgNPs were placed overnight in a $4^{\circ} \mathrm{C}$ refrigerator.

2.4. General Procedures. In a $5 \mathrm{~mL}$ centrifugal tube, $300 \mu \mathrm{L}$ of HAc-NaAc buffer ( $\mathrm{pH}$ 5.6), appropriate distilled water, different volume working solution of $\mathrm{Hg}$ (II) $\left(2 \times 10^{-4} \mathrm{~mol} / \mathrm{L}\right)$, and $390 \mu \mathrm{L}$ AgNPs solution were added. The total volume of the mixed solution was $3 \mathrm{~mL}$. After the solution was thoroughly mixed, absorbance spectrum was recorded by UV-vis spectrophotometer immediately.

\section{Results and Discussion}

3.1. Characteristics of Absorption Spectra. AgNPs, as probe, are used to detect $\mathrm{Hg}$ (II) ion based on the blue shift of the maximum absorption wavelength. As shown in Figure 1, single AgNPs characterized at $394 \mathrm{~nm}$ (curve 1), when $\mathrm{Hg}$ (II) ion was added, the maximum absorption wavelength blue shifted, and the absorption intensity gradually decreased with increasing the $\mathrm{Hg}$ (II) ion content (curves 2-5). It is observed that the solution color gradually changed from yellow to colorless (the insert picture). Moreover, over the range from $2.0 \times 10^{-7}$ to $6.0 \times 10^{-6} \mathrm{~mol} / \mathrm{L}$, the blue shift was in proportion to the $\mathrm{Hg}$ (II) concentration. Generally, when cations are adsorbed on the surface of AgNPs, the characteristic peak will red shift and broaden [20]. However, blue shift was observed in this experiment, which was induced by $\mathrm{Hg}$ (II) ion.

In the preparation of AgNPs, sodium borohydride was reducing agent and in excess in order to keep AgNPs dispersed and stable. When $\mathrm{Hg}$ (II) ion was added into AgNPs solution, the in excess sodium borohydride could also reduce $\mathrm{Hg}(\mathrm{II})$ to $\mathrm{Hg}(0) . \mathrm{Hg}(0)$ atoms wrapped around silver nanoparticles and amalgam was generated, leading to the blue shift of the maximum peak $[11,20]$. Up to now, articles about amalgam have been published. Amalgam could be formed between mercury and other metals, such as gold, silver, copper, tin, and zinc [21]. Silver or gold with mercury can form bimetallic colloids or the so-called amalgam and lead to blue shift of the absorption peak [11, 22]. In our experiment, the reaction of $\mathrm{Hg}$ (II) and AgNPs mixture resulted in the formation of silver amalgam and the blue shift. The images of scanning electron microscopy were carried out to demonstrate the above results. As shown in Figure 2, single AgNPs (Figure 2(a)) are dispersed well. However, the particle diameter gradually becomes larger when the $\mathrm{Hg}$ (II) ion concentration increases (Figures 2(b), 2(c), and 2(d)). It indicates that AgNPs are gradually wrapped and silver amalgam forms.

3.2. The Influence of Acidity. In order to determine the influence of $\mathrm{pH}$ on the system, the reaction was carried out at different $\mathrm{pH}$ value and the absorption was measured. According to the $\mathrm{Ksp}$ of $\mathrm{Hg}(\mathrm{OH})_{2}$, we calculated that $\mathrm{Hg}$ (II) would deposit when $\mathrm{pH}$ was more than 6.24. So the acidity was controlled by HAc-NaAc buffer and keeping $\mathrm{pH}$ less than 6.24. Experimental results are shown in Figure 3. It is displayed that the acidity has slight influence on the experimental results. When the $\mathrm{pH}$ was near weak acidity, the blue-shifted maximum absorption wavelength was a little larger than that near the strong acidity. Finally, pH 5.6 was chosen to be our experimental condition.

3.3. The Influence of the Concentration of AgNPs. To select the optimal AgNPs concentration in our experimental system, we also studied different concentration of AgNPs. The results can be seen in Figure 4. First, when the concentration was over the range from $2.0 \times 10^{-5} \mathrm{~mol} / \mathrm{L}$ to $7.0 \times 10^{-5} \mathrm{~mol} / \mathrm{L}$, the blue shift of the maximum absorption wavelength is nearly the same. When its concentration is larger than $7.0 \times$ $10^{-5} \mathrm{~mol} / \mathrm{L}$, the blue shift is sharply decreased. Second, the color was stronger with increasing the AgNPs concentration. Considering the two factors, we choose $6.5 \times 10^{-5} \mathrm{~mol} / \mathrm{L}$ as the optimal concentration of AgNPs.

3.4. Selectivity and Stability of the Reactive System. We also studied the selectivity and stability of the system. The experimental data are shown in Figures 5 and 6. Figure 5 indicates that the reactive system has a very good selectivity on $\mathrm{Hg}$ (II) 


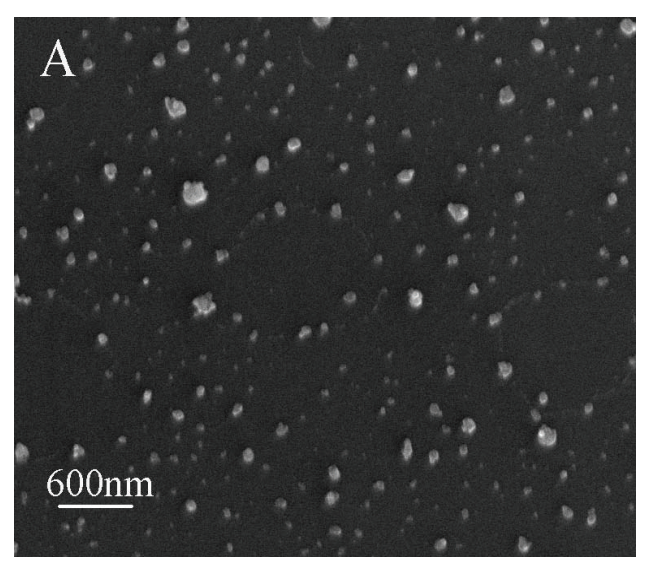

(a)

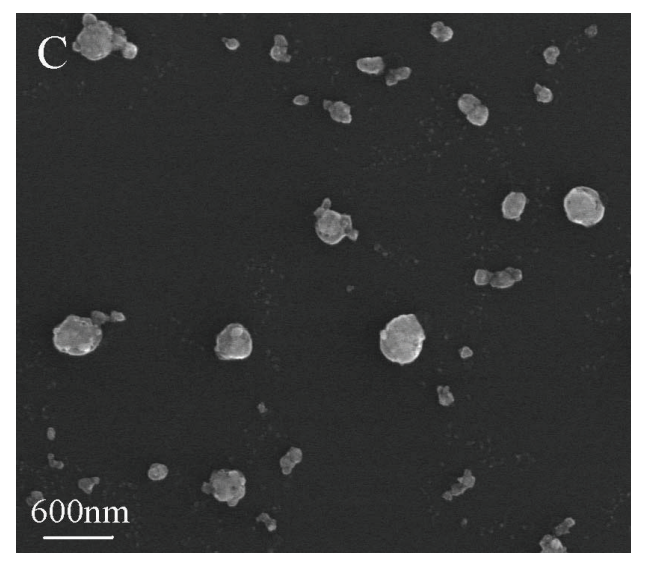

(c)

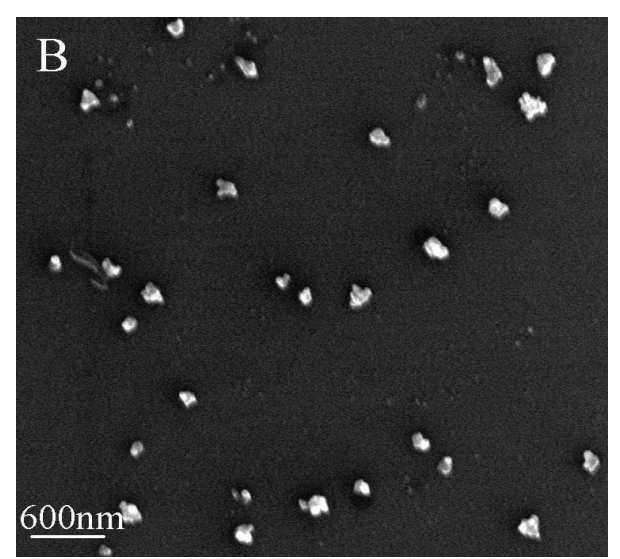

(b)

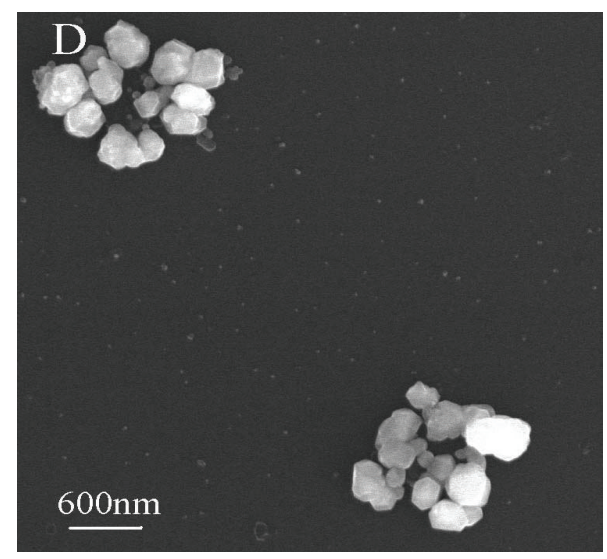

(d)

Figure 2: The scanning electron microscopy of AgNPs in the absence and presence of $\mathrm{Hg}$ (II) ion. Concentration: AgNPs: $6.5 \times 10^{-5} \mathrm{~mol} / \mathrm{L}$; $\mathrm{Hg}$ (II) ion (from A to D, $\times 10^{-6} \mathrm{~mol} / \mathrm{L}$ ): 0, 2.0, 4.0, 6.0; HAc-NaAc buffer (pH 5.6).

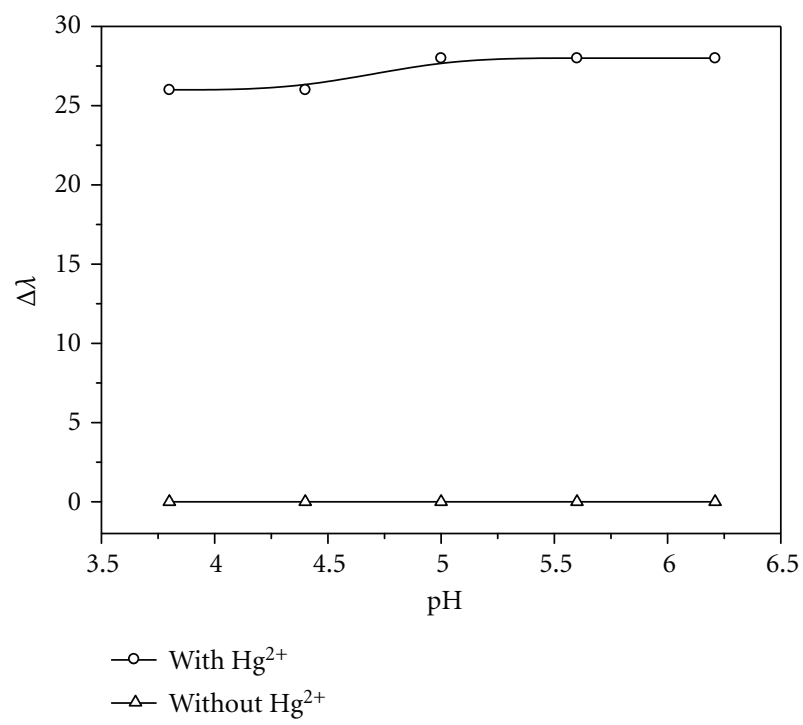

Figure 3: The influence of acidity. Concentration: AgNPs: $5.0 \times$ $10^{-5} \mathrm{~mol} / \mathrm{L}^{-1}$; $\mathrm{Hg}$ (II) ion: $6.0 \times 10^{-6} \mathrm{~mol} / \mathrm{L}$; the $\mathrm{pH}$ of HAc-NaAc buffer (from 1 to 5 ): $3.8,4.4,5.0,5.6,6.2$.

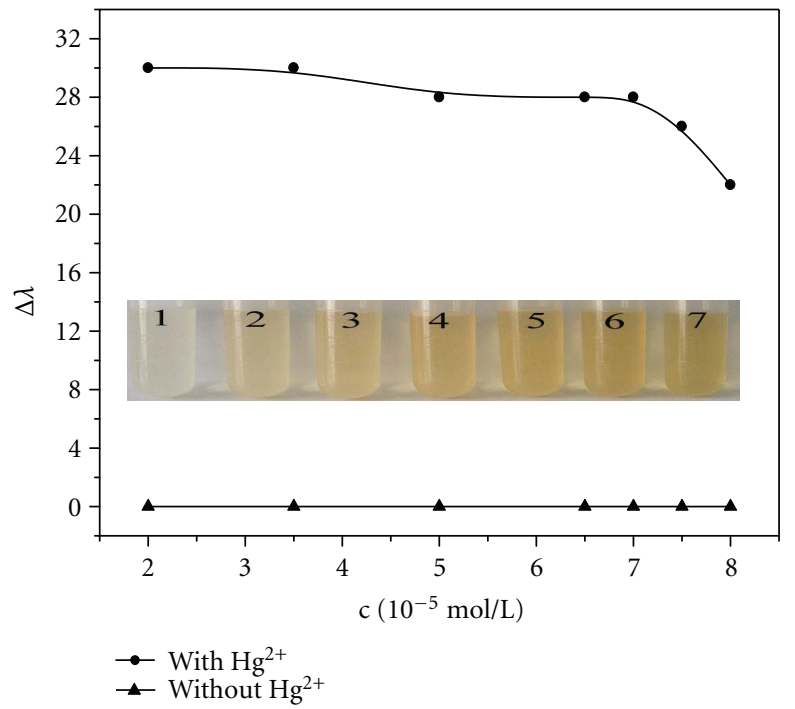

FIGURE 4: Effect of the AgNPs concentration. Concentration: AgNPs $\left(\times 10^{-5} \mathrm{~mol} / \mathrm{L}\right): 2.0,3.5,5.0,6.5,7.0,7.5,8.0$, respectively; $\mathrm{Hg}$ (II) ion: $6.0 \times 10^{-6} \mathrm{~mol} / \mathrm{L}$; HAc-NaAc buffer ( $\mathrm{pH} 5.6$ ). The inset picture displays color change with different concentration of AgNPs. 


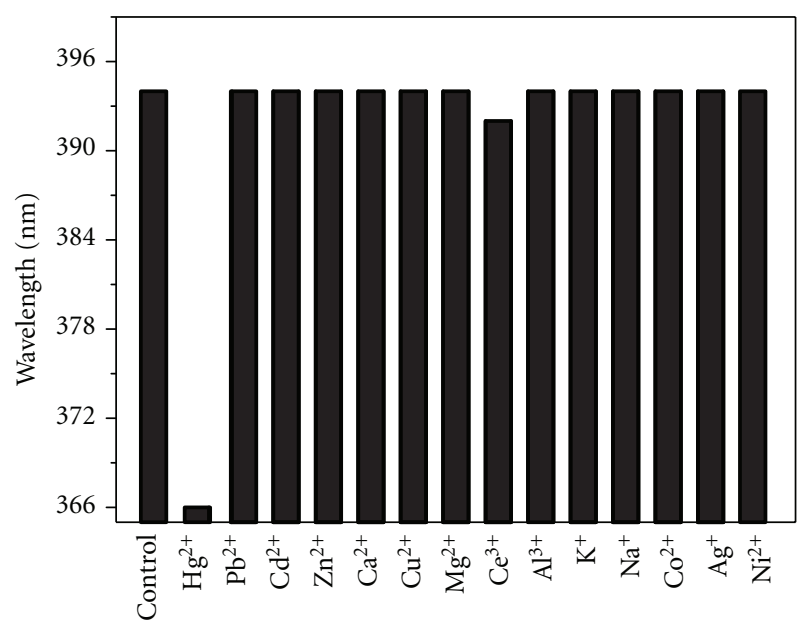

FIGURE 5: Selectivity of the reactive system. Concentration: AgNPs: $6.5 \times 10^{-5} \mathrm{~mol} / \mathrm{L} ; \mathrm{Hg}$ (II) ion: $6.0 \times 10^{-6} \mathrm{~mol} / \mathrm{L}$; the other metal ions: $6.7 \times 10^{-6} \mathrm{~mol} / \mathrm{L}$; HAc-NaAc buffer $(\mathrm{pH} 5.6)$.

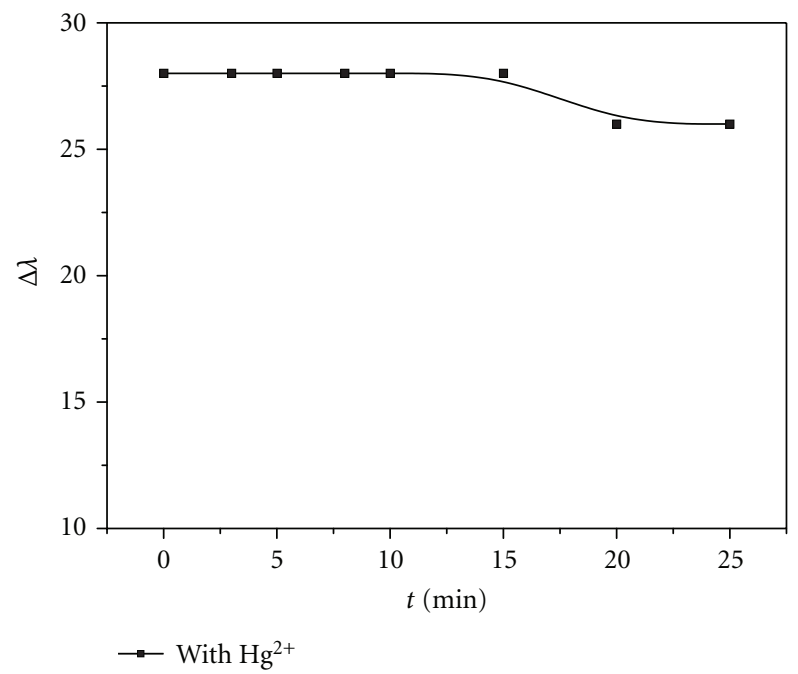

Figure 6: Stability of the reactive system. Concentration: AgNPs: $6.5 \times 10^{-5} \mathrm{~mol} / \mathrm{L} ; \mathrm{Hg}$ (II) ion: $6.0 \times 10^{-6} \mathrm{~mol} / \mathrm{L} ; t(\mathrm{~min}): 0,3,5,8$, 10, 15, 20, 25, respectively; HAc-NaAc buffer ( $\mathrm{pH} 5.6$ ).

ion. When $\mathrm{Hg}$ (II) ion is added, the maximum absorption wavelength of AgNPs significantly changed. While other metal ions are added, respectively, including $\mathrm{Pb}^{2+}, \mathrm{Ni}^{2+}$, $\mathrm{Cd}^{2+}, \mathrm{Zn}^{2+}, \mathrm{Ca}^{2+}, \mathrm{Cu}^{2+}, \mathrm{Mg}^{2+}, \mathrm{Ce}^{3+}, \mathrm{Al}^{3+}, \mathrm{K}^{+}, \mathrm{Ag}^{+}, \mathrm{Na}^{+}$, $\mathrm{Co}^{2+}$, the characteristic peak still stay at $394 \mathrm{~nm}$, except $\mathrm{Ce}^{3+}$, which only induced a weak blue shift of $2 \mathrm{~nm}$.

In addition, chloride $\left(\mathrm{Cl}^{-}\right)$caused great interference on our experiment, which could be eliminated easily by $\mathrm{Ag}_{2} \mathrm{O}$ [23]. So a simple pretreatment was needed to screen $\mathrm{Cl}^{-}$ before determination.

We investigated the stability of the reactive system. It could be stable for at least $15 \mathrm{~min}$, as shown in Figure 6 . In the presence of $\mathrm{Hg}$ (II) ion, silver amalgam was formed quickly, and the particle diameter increased. It was easy to

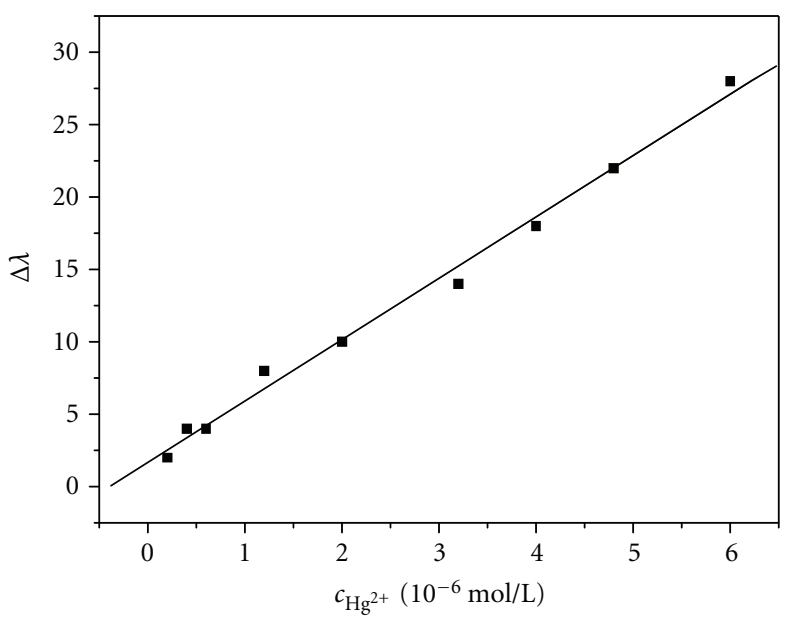

Figure 7: The blue shift of the maximum absorption wavelength of AgNPs and $\mathrm{Hg}$ (II) ion concentration. A linear correlation exists over the range of $2.0 \times 10^{-7}-6.0 \times 10^{-6} \mathrm{~mol} / \mathrm{L}$.

TABLE 1: The results of synthetic samples.

\begin{tabular}{|c|c|c|c|c|}
\hline Samples & Main interferes & $\begin{array}{c}\text { Found } \\
(\mu \mathrm{mol} / \mathrm{L})\end{array}$ & $\begin{array}{c}\text { Recovery } \\
(\%)\end{array}$ & $\begin{array}{c}\text { R.S.D. }(\%) \\
(n=5)\end{array}$ \\
\hline 1 & $\begin{array}{c}\mathrm{K}^{+}, \mathrm{Cd}^{2+}, \mathrm{Ca}^{2+} \\
\mathrm{Al}^{3+}\end{array}$ & $1.73-2.20$ & $86.4-110.0$ & 9.8 \\
\hline 2 & $\begin{array}{c}\mathrm{Cu}^{2+}, \mathrm{Mg}^{2+} \\
\mathrm{Pb}^{2+}, \mathrm{Na}^{+}\end{array}$ & $2.67-3.38$ & $83.5-105.6$ & 11.2 \\
\hline 3 & $\begin{array}{l}\mathrm{Zn}^{2+}, \mathrm{Ce}^{3+}, \mathrm{Ag}^{+}, \\
\quad \mathrm{Co}^{2+}, \mathrm{Ni}^{2+} .\end{array}$ & $4.32-4.56$ & $90.0-95.0$ & 3.0 \\
\hline
\end{tabular}

AgNPs: $6.5 \times 10^{-5} \mathrm{~mol} / \mathrm{L}$; other metal ions: $6.7 \times 10^{-6} \mathrm{~mol} / \mathrm{L} ; \mathrm{HAc}-\mathrm{NaAc}$ buffer ( $\mathrm{pH}$ 5.6).

deposit down for larger particles. Therefore, the reactive system could not be stable for long time. The images of scanning electron microscopy also indicated our explanation (seen in Figure 2).

3.5. Determination of $\mathrm{Hg}$ (II) Ion. Under the optimal conditions, the calibration curve for detecting $\mathrm{Hg}$ (II) ion was established. There was a good linear correlation between the blue shift of maximum absorption wavelength and the concentration of $\mathrm{Hg}$ (II) ion over the range of $2.0 \times$ $10^{-7} \mathrm{~mol} / \mathrm{L}$ to $6.0 \times 10^{-6} \mathrm{~mol} / \mathrm{L}$, with the limit of detection $(3 \sigma)$ of $6.6 \times 10^{-9} \mathrm{~mol} / \mathrm{L}$. And its standard regression equation was $\Delta \lambda=1.6708+4.23943 c_{\mathrm{Hg}^{2+}}(r=0.9961, n=$ 9), as shown in Figure 7.

According to the calibration curve, three synthetic samples of $\mathrm{Hg}$ (II) ion containing some other metal ions were detected. The measurement results are listed in Table 1. It is shown that the recovery is between $83.5 \%$ and $110.0 \%$, and the R.S.D is lower than $11.2 \%$.

\section{Summary}

Hg (II) ion can interact with AgNPs solution prepared by sodium borohydride. In the presence of $\mathrm{Hg}$ (II) ion, 
the AgNPs solution displays color change and blue shift of the maximum absorption wavelength, and thus we propose a rapid, simple, and highly selective method for detecting $\mathrm{Hg}$ (II) ion. The influence of acidity and the concentration of AgNPs, selectivity, and stability are all studied for the reactive system. Here, we expect that it will become a promising technique to determine $\mathrm{Hg}$ (II) ion.

\section{Acknowledgments}

All authors herein are grateful to the support from the $\mathrm{Mu}$ nicipal Natural Science Foundation of Chongqing (CSTC, no. 2007BB0049) and the Municipal Science and Technology Committee of Chongqing.

\section{References}

[1] J. W. Sekowski, L. H. Malkas, Y. Wei, and R. J. Hickey, "Mercuric ion inhibits the activity and fidelity of the human cell dna synthesome," Toxicology and Applied Pharmacology, vol. 145, no. 2, pp. 268-276, 1997.

[2] L. Manganiello, A. Ríos, and M. Valcárcel, "A method for screening total mercury in water using a flow injection system with piezoelectric detection," Analytical Chemistry, vol. 74, no. 4, pp. 921-925, 2002.

[3] S. Si, A. Kotal, and T. K. Mandal, "One-dimensional assembly of peptide-functionalized gold nanoparticles: an approach toward mercury ion sensing," Journal of Physical Chemistry C, vol. 111, no. 3, pp. 1248-1255, 2007.

[4] J. S. Lee, M. S. Han, and C. A. Mirkin, "Colorimetric detection of mercuric ion (hg2+) in aqueous media using dna functionalized gold nanoparticles," Angewandte Chemie, vol. 46, no. 22, pp. 4093-4096, 2007.

[5] C. J. Yu, T. L. Cheng, and W. L. Tseng, "Effects of mn2+ on oligonucleotide-gold nanoparticle hybrids for colorimetric sensing of hg2+: improving colorimetric sensitivity and accelerating color change," Biosensors and Bioelectronics, vol. 25, no. 1, pp. 204-210, 2009.

[6] X. Xu, J. Wang, K. Jiao, and X. Yang, "Colorimetric detection of mercury ion (hg2+) based on dna oligonucleotides and unmodified gold nanoparticles sensing system with a tunable detection range," Biosensors and Bioelectronics, vol. 24, no. 10, pp. 3153-3158, 2009.

[7] D. Li, A. Wieckowska, and I. Willner, "Optical analysis of $\mathrm{Hg}^{2+}$ ions by oligonucleotide-gold-nanoparticle hybrids and DNAbased machines," Angewandte Chemie, vol. 47, no. 21, pp. 3927-3931, 2008.

[8] I. B. Kim and U. H. F. Bunz, "Modulating the sensory response of a conjugated polymer by proteins: an agglutination assay for mercury ions in water," Journal of the American Chemical Society, vol. 128, no. 9, pp. 2818-2819, 2006.

[9] M. Leermakers, W. Baeyens, P. Quevauviller, and M. Horvat, "Mercury in environmental samples: speciation, artifacts and validation," Trends in Analytical Chemistry, vol. 24, no. 5, pp. 383-393, 2005.

[10] P. Ugo, S. Zampieri, L. M. Moretto, and D. Paolucci, “Determination of mercury in process and lagoon waters by inductively coupled plasma-mass spectrometric analysis after electrochemical preconcentration: comparison with anodic stripping at gold and polymer coated electrodes," Analytica Chimica Acta, vol. 434, no. 2, pp. 291-300, 2001.
[11] M. Rex, F. E. Hernandez, and A. D. Campiglia, "Pushing the limits of mercury sensors with gold nanorods," Analytical Chemistry, vol. 78, no. 2, pp. 445-451, 2006.

[12] C. Y. Lin, C. J. Yu, Y. H. Lin, and W. L. Tseng, "Colorimetric sensing of silver(I) and mercury(II) ions based on an assembly of tween 20-stabilized gold nanoparticles," Analytical Chemistry, vol. 82, no. 16, pp. 6830-6837, 2010.

[13] R. Bhattacharya and P. Mukherjee, "Biological properties of "naked" metal nanoparticles," Advanced Drug Delivery Reviews, vol. 60, no. 11, pp. 1289-1306, 2008.

[14] R. J. Stokes, A. Macaskill, P. Johan Lundahl, W. Ewen Smith, K. Faulds, and D. Graham, "Quantitative enhanced raman scattering of labeled dna from gold and silver nanoparticles," Small, vol. 3, no. 9, pp. 1593-1601, 2007.

[15] J. S. Lee, A. K. R. Lytton-Jean, S. J. Hurst, and C. A. Mirkin, "Silver nanoparticle-oligonucleotide conjugates based on dna with triple cyclic disulfide moieties," Nano Letters, vol. 7, no. 7, pp. 2112-2115, 2007.

[16] S. P. Tai, Y. Wu, D. B. Shieh et al., "Molecular imaging of cancer cells using plasmon-resonant-enhanced third-harmonicgeneration in silver nanoparticles," Advanced Materials, vol. 19, no. 24, pp. 4520-4523, 2007.

[17] K. Vimala, K. Samba Sivudu, Y. Murali Mohan, B. Sreedhar, and K. Mohana Raju, "Controlled silver nanoparticles synthesis in semi-hydrogel networks of poly(acrylamide) and carbohydrates: a rational methodology for antibacterial application," Carbohydrate Polymers, vol. 75, no. 3, pp. 463-471, 2009.

[18] M. Rai, A. Yadav, and A. Gade, "Silver nanoparticles as a new generation of antimicrobials," Biotechnology Advances, vol. 27, no. 1, pp. 76-83, 2009.

[19] R. C. Doty, T. R. Tshikhudo, M. Brust, and D. G. Fernig, "Extremely stable water-soluble ag nanoparticles," Chemistry of Materials, vol. 17, no. 18, pp. 4630-4635, 2005.

[20] L. Katsikas, M. Gutiérrez, and A. Henglein, "Bimetallic colloids: silver and mercury," Journal of Physical Chemistry, vol. 100, no. 27, pp. 11203-11206, 1996.

[21] H. A. Acciari, A. C. Guastaldi, and C. M. A. Brett, "On the development of the electrochemical potentiokinetic method," Electrochimica Acta, vol. 46, no. 24-25, pp. 3867-3877, 2001.

[22] A. Henglein and C. Brancewicz, "Absorption spectra and reactions of colloidal bimetallic nanoparticles containing mercury," Chemistry of Materials, vol. 9, no. 10, pp. 2164-2167, 1997.

[23] H. T. Fu, L. M. Zhao, M. Luo, H. Y. Zhang, and J. Zhang, "Determination of chloracetic acids in drinking water by ion chromatography using silver oxide as precipitant eliminating interference of chlorate in matrix," Chinese Journal of Analytical Chemistry, vol. 36, no. 10, pp. 1407-1410, 2008. 


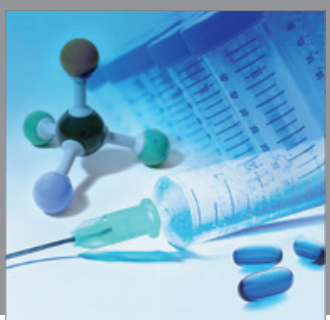

International Journal of

Medicinal Chemistry

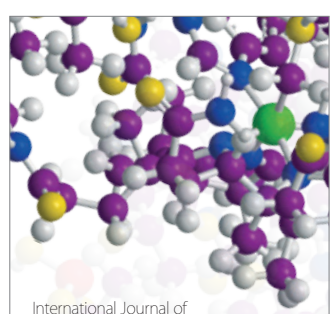

Carbohydrate Chemistry

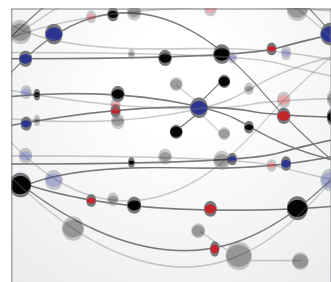

The Scientific World Journal
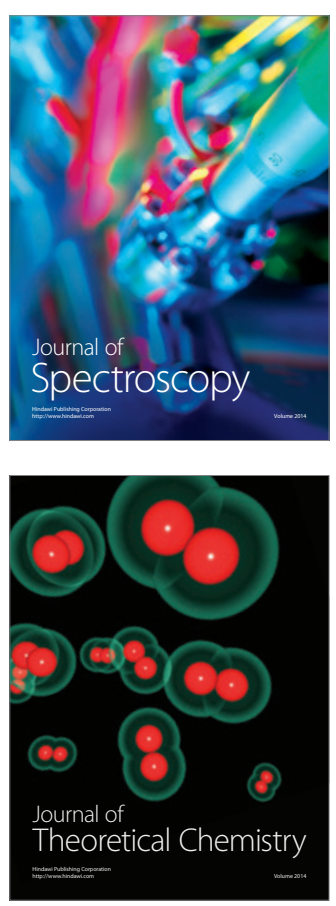
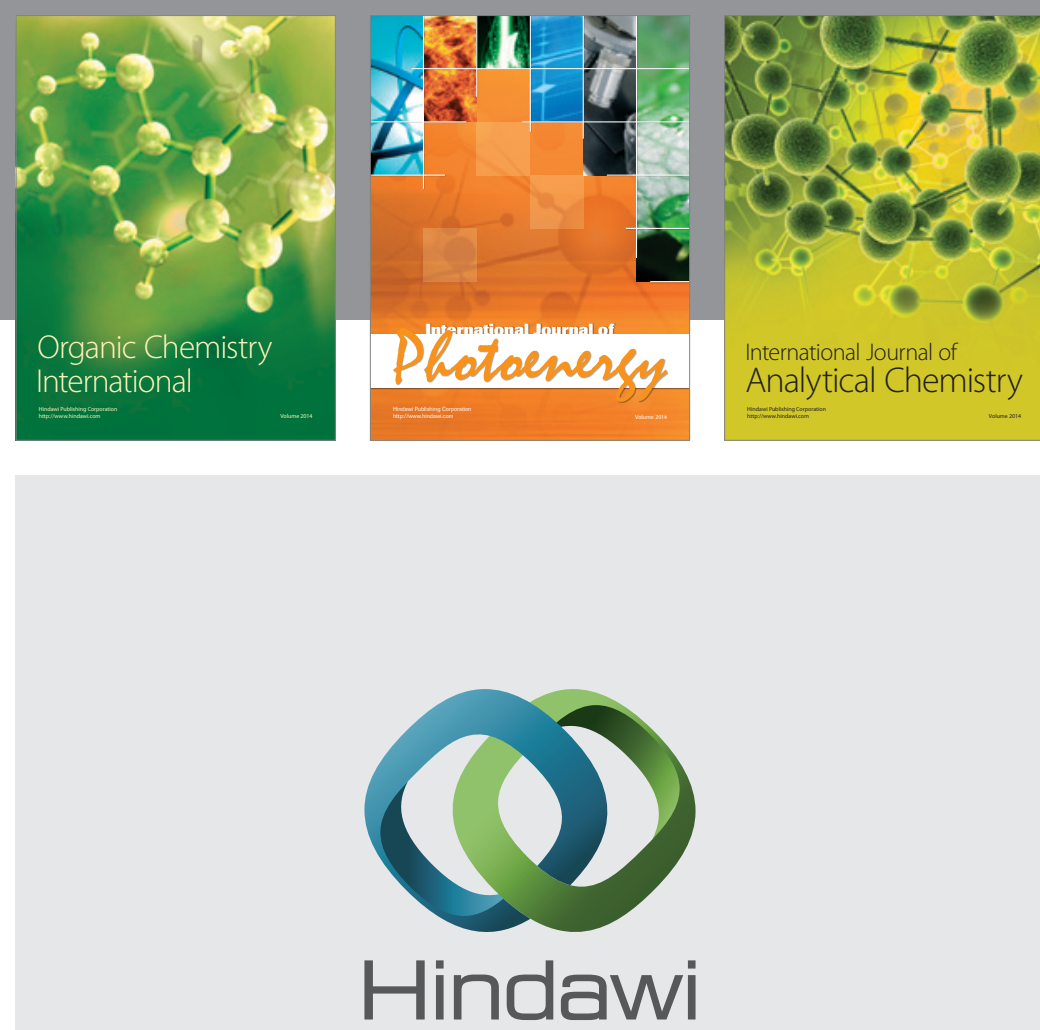

Submit your manuscripts at

http://www.hindawi.com
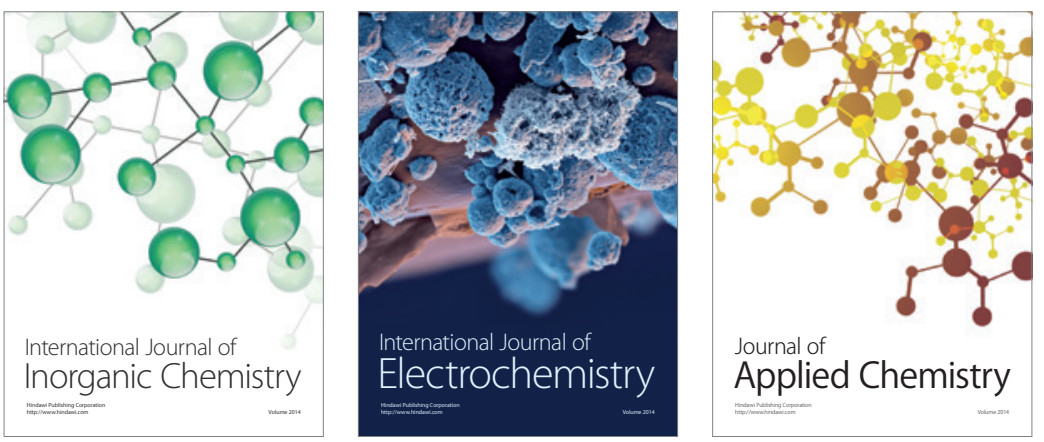

Journal of

Applied Chemistry
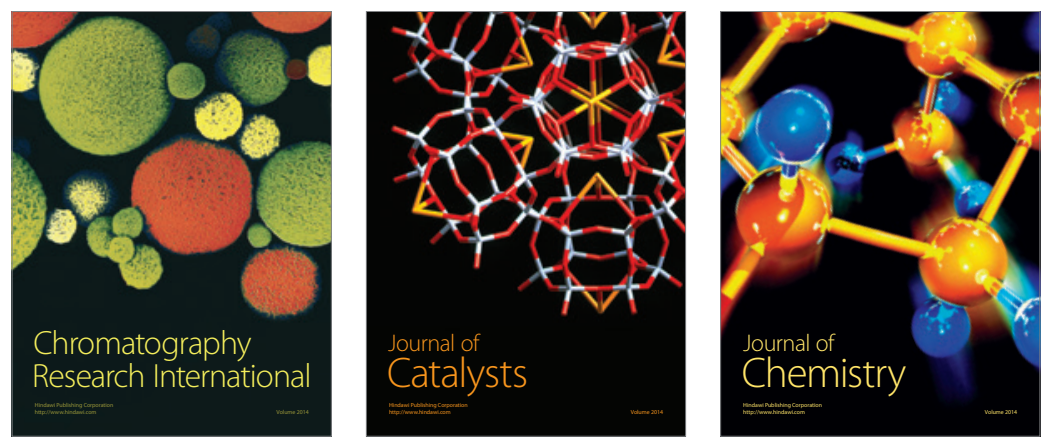
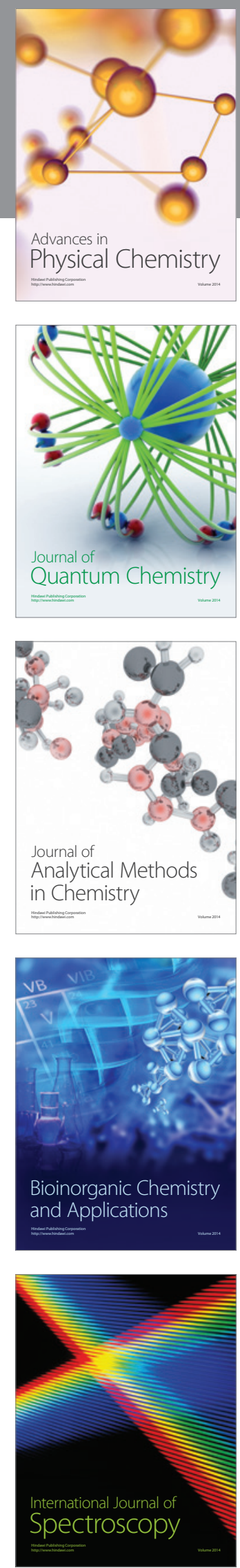